
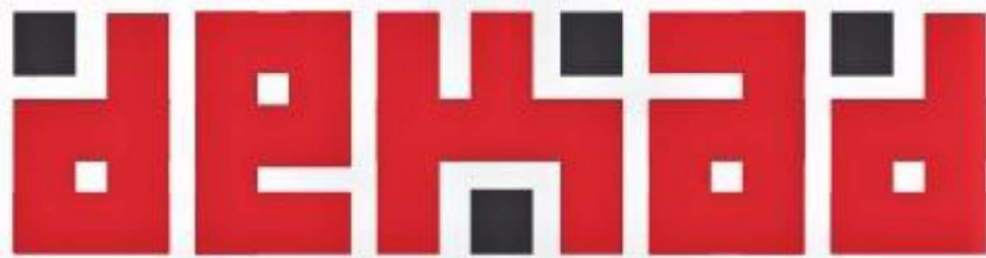

INTERNATIONAL JOURNAL OF LANGUAGE, LITERATURE AND CULTURE RESEARCHES

МЕЖДУНАРОДНЫЙ ЖУРНАЛ ЛИНГВИСТИЧЕСКИХ,

ЛИТЕРАТУРОВЕПЧЕСКИХ И КУЛЬТУРОЛОГИЧЕСКИХ ИССЛЕЛОВАНИЙ

Vol: 4, Issue: 1, 2021

Sayfa-Page: $125-140$

E-ISSN: 2667-4262

BİR DÖNEME DAMGA VURAN ÜÇ AVANGART DERGİ: LEONARDO, LA VOCE VE LACERBA

THREE AVANT-GARDE JOURNALS WHICH LEFT THEIR SEAL IN AN ERA: LEONARDO, LA VOCE AND LACERBA

Barış YÜCESAN*

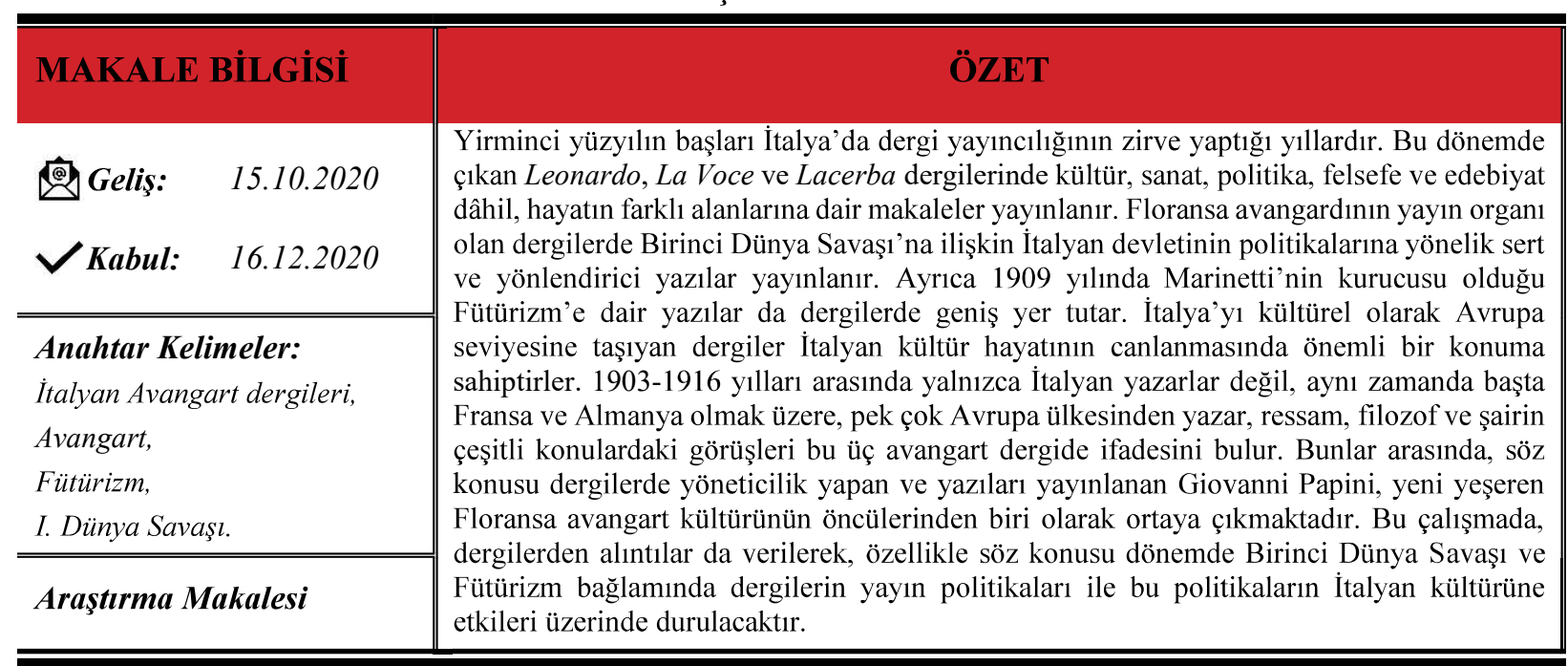

Received: 15.10 .2020

The beginning of the twentieth century was the peak years of journal publishing in Italy. In journals of this period like Leonardo, La Voce, and Lacerba, articles are published on different areas of life including culture, art, politics, philosophy and literature. In the

Accepted: 16.12 .2020 journals, which are the media organs of the Florentine avant-garde, are published critical and directive articles on the policies of the Italian State regarding the First World War. Besides, the articles on Futurism, founded by Marinetti in 1909, have wide coverage. The journals that take Italy to the European level culturally, have an important role in the revival

Keywords: of Italian cultural life. Between 1903-1916 the views of not only Italian writers, but also writers, philosophers and poets from other European countries, especially France and Germany, find their expression on various subjects in these three avant-garde journals. Among these people, Giovanni Papini who is director and publishes his works in these journals emerges as one of the pioneers of fledgling Florentine avant-garde culture. In the present study, the publication policies of the journals in the context of World War I and Futurism and the effects of these policies on Italian culture will be emphasized by giving citations from the journals.

* Arş. Gör., Ankara Üniversitesi, Dil ve Tarih-Coğrafya Fakültesi, Batı Dilleri ve Edebiyatları Bölümü, İtalyan Dili ve Edebiyatı Anabilim Dalı, Ankara / Türkiye, E-mail: byucesan@ankara.edu.tr.

ORCID (D) https://orcid.org/0000-0002-1776-9815.

Bu makaleyi şu şekilde kaynak gösterebilirsiniz / To cite this article (APA):

Yücesan, Barıș (2021). "Bir Döneme Damga Vuran Üç Avangart Dergi: Leonardo, La Voce ve Lacerba". Uluslararası Dil,

Edebiyat ve Kültür Araştırmaları Dergisi (UDEKAD), 4 (1): 125-140. DOI: http://dx.doi.org/10.37999/udekad.912994. 


\section{Extended Abtract}

The first quarter of the twentieth century is a period in which there have been profound changes regarding the cultural and social spheres in Italy as so throughout the world. These changes experienced in various spheres of life are a result of the economic and political developments that took place in the nineteenth century. Within this context, the journals that emerged throughout the Italian peninsula are an important instrument in understanding the spirit of this period in question. The journals Leonardo (1903-1907), La Voce (1908-1916), and Lacerba (1913-1915) provide illuminating information that aids researchers in comprehending what happened in Italy during the early years of the twentieth century, including the reasons that led Italy to join the First World War.

First of all, when the Leonardo, founded by Papini and Prezzolini, is considered, it becomes clear that the journal not only appeals to Italian intellectual circles but also attracts the attention of prominent figures such as William James, F.C.S. Schiller, and Henri Bergson. The authors of the journal, which is a part of the Florence Futurist movement, wish to restore Italy to its rightful place as a world power, as it was during the Roman Empire. In line with this objective, they are committed to their goal of going beyond the past ideals and carrying the country further in the cultural sphere. They prefer innovation, speed, and modernism over the burden and outdatedness of the past for this reason. The journal, which is dominated by the pragmatist movement, serves as a significant cornerstone in the maturing of the Futurism movement, which will begin in 1909. It almost prepares society for this new period to come. The period in question necessitates drastic reforms in literature, art, social life, and politics for a pioneering and powerful society to live up to its high ideals. In short, the ideology of the journal is to forget the past, make one forget, and achieve a position of leadership in social and cultural life in the future. This requires the adoption of modern values.

La Voce plays a significant role in advancing the cultural heritage and existing cultural goals inherited from previous journals. Beyond culture, one of the objectives of the journal members is the desire to announce the recommendations and criticisms about political life to the addressees of the subject by fostering a social consensus. The inadequacies of the foresight and culture of the rulers and bourgeoisies are criticized in terms of modernism. It is advocated that this circumstance should be changed by the establishment of a new ruling class that is aware of the period's requirements.

Assimilating prominent European literary and philosophical movements and values and introducing and popularize them in Italy is aimed. For this very reason, a vigorous effort is put into developing a new intellectual structure in which avant-garde culture takes center stage to seize the spirit of the moment.

Additionally, the worldviews of thinkers who are self-assured and persistent enough to shape a country's political course are not identical. There is an ideal that can unite intellectuals from different walks of life in a common cause. Italy, according to the said ideal, should take part in the First World War and provide a fertile environment for the ultimate change. So much so that in some issues of the journal, a sort of pressure is put on the government for the necessity of participating in the war. For instance, the state of Italia, which fell behind the great powers of Europe in the colonial race, plans to colonize Libya by separating it from the Ottoman Empire. The reason why the war is wanted so much at the level of warmongering stems from the belief that the country will enter into a new and more modern era by this means, which is always desired.

The journal, which includes extremely critical articles, can be considered an activist publication. The common ideal in question enables the society to unite in line with an objective. Some authors even serve on the front lines and perish in the war. Aiming to turn the painful events experienced in the modern age into opportunities, this group continues to make substantial contributions to Italian journalism and the world of thought by dividing within itself and causing the birth of different magazines.

The journal Lacerba, which is the last subject of the study, is regarded as one of the most important publications of Italian avant-garde culture. Many Italian and European writers, painters, and artists contribute to the journal with writings and illustrations. Among the most well-known painters, Pablo Picasso also takes place in the journal. Therefore, it can be qualified as a journal that managed to arouse the interest of different art circles of the period. 
The fact that the journal attracts such attention also facilitates the spread of supported views throughout Europe, particularly in Italy. Its publication goal can be summarized as follows: ensuring the country's political integrity and denying some traditional values for the regeneration in the cultural sphere. In this context, Lacerba can be regarded as one of the leading publications of the Futurist movement.

Beyond cultural renewal, political goals are pursued. The desire to be a party in the First World War is frequently expressed by Lacerba authors. From the author's statements, it is understood that they considered the war as an opportunity on the way to "cleansing the world." The journal management lists their war-related requests in general in four items. It is worth noting that it had a significant influence on the political and cultural life of the period.

In conclusion, the three journals discussed had a significant impact in setting political and cultural course in Italy in the early twentieth century. It is understood that they have aided the industrial development of Italy and served as a propaganda tool regarding expanding the country's territory following the war. These journals are an important tool for in terms of Italian intellectuals, who embraced the traditional culture, to become involved in the world of ideas, thought, and art in the twentieth century.

\section{Giriş}

Henüz yirminci yüzyılın ilk yılları yaşanırken İtalya siyasi ve kültürel bakımdan oldukça hareketli yıllar geçirir. Ulus olma bağlamında birliğini diğer Avrupa devletlerine göre geç tamamlamış (1861) olan resmi adıyla İtalya Krallığı'nda, söz konusu birleşmenin beraberinde getirdiği modernleşme, diğer bir deyişle muasır medeniyet seviyesine ulaşma çabası, görece hızlı bazı siyasî, idarî, iktisadî ve kültürel değișim ve yeniliklerin yapılmasını zarurî kılmıştır. Öyle ki, İspanya, Fransa ve Avusturya gibi, zamanın büyük Avrupa devletlerinin siyasî müdahaleleri altında varlıklarını sürdüren İtalyan şehir devletleri, yarımadada sağlanan birliğin neticesinde hızlıca devlet kurumlarını oluşturma sürecine girerek diğer Avrupa devletlerine göre geç kaldıkları sömürge bulma yarışına katılır. Pek çok açıdan sancılı geçen bu süreç, ister istemez dönemin siyasî ve kültürel nabzını tutan dergilerde, gazetelerde, kısaca basın-yayın organlarında genişçe yer bulur.

Yirminci yüzyılın başları düşünüldüğünde, İtalya gibi bir ülkenin dış politikasını, toplumun sosyal ve kültürel gelişimini entelektüellerin düşünce yapısını irdeleyerek incelemek, dolayısıyla İtalya'nın geçirdiği dönüşümü daha iyi kavrayabilmek için dönemin basın-yayın organlarına bakmak gerekir. Özellikle de söz konusu yüzyılın ilk yılları itibariyle, dergiler yüzyılı olarak adlandırılan, kültürel ve sosyal alanda önemli değişikliklerin yaşandığı ve düşünce akımlarının yeşerdiği ortamda İtalyan toplumunun durumunu derinlemesine incelemek için veri teşkil edebilecek çok sayıda derginin olduğu gerçeğinden hareketle araştırma yapmak güvenilir ve kapsayıcı sonuçlara ulaşabilmek adına önemli bir adım olacaktır.

Bu noktadan hareketle şunu ifade etmek mümkündür: Bazı dergilerde İtalyan devletinin sömürge bulabilmesi adına hangi ülkeye ne şekilde müdahale etmesi gerektiğini gösterecek kadar ayrıntılı yazılar yayınlanmıştır. Dergilerde yalnızca siyasî konular üzerine kaleme alınan yazılar yayınlanmaz, aynı zamanda edebî ve kültürel konularda da çok sayıda makale yayınlanır. Dergilerde yazan pek çok edebiyatçı şu hususun farkındadır: Yazarlara göre, İtalyan edebiyatı geçmişten ve geleneklerinden beslenen bir yapı olarak modern çağın beraberinde getirdiği bazı yeniliklere açık olmalı, hatta Avrupa'da kültürel alanda yenilik konusunda İtalya öncülük etmelidir. Bu nedenle, "İtalyan edebiyatı temsilcileri aracılığılla Avrupa sahnesine çıkartılmalıdır” görüşü hâkimiyet kazanır. Yenilikçi bir bakış açısına sahip yazar ve 
entelektüeller, İtalya'nın Avrupa'da kendine geçmişteki ihtişamına yaraşır bir şekilde yer bulup liderlik konumuna gelmesi gerektiği görüşünü savunmuştur. Bu ideal bağlamında, farklı düşünce ve felsefe akımlarına dâhil olan pek çok dergi ve gazete yayınlandığ

Kültürel faaliyetlerin gittikçe artan bir ivmeyle hız kazandığı yirminci yüzyılın ilk çeyreğinde, özellikle Birinci Dünya Savaşı'na giden süreçte, birbirinin peşi sıra yayın hayatına başlayan dergiler kurulur. Bu atmosferde yirminci yüzyıl İtalyan edebiyatında önemli konuma sahip olacak yazar, şair ve düşünürler yayın hayatına başladıkları ilk yazılarını söz konusu bu dergilerde yayınlarlar. Bu kültürel ortamda yazarlar kendi politik, edebî, felsefi görüşlerine yakın olan dergileri seçerler ve pek çok konudaki görüşlerini, bazen sert bir üslup kullanarak dergi satırlarına yansıtmaktan geri durmazlar. Söz konusu hususta başı çeken İtalyan şehirlerinden biri de Floransa'dır. Nitekim şehrin tarihine bakıldığında, gerek günümüzde konuşulan İtalyancanın doğduğu ve geliştiği bölge olması, gerek Dante, Petrarca, Boccaccio gibi İtalyan edebiyatı ve dünya edebiyatının öncü şairlerine ev sahipliği yapması ve akabinde Rönesans'ın doğduğu topraklar olması bakımından kültürel ve edebi yaşam üzerinde etkisi oldukça yoğun hissedilen bir yerdir. Var olan bu kültürel miras dikkate alındığında, şehrin yirminci yüzyılda da kültürel merkezlerden biri olmaya devam etmesinin sebebi anlaşılmaktadır.

Bu çalışmanın konusu olan ve dönemin İtalya'sında oldukça ses getiren tartışmalara ve fikirlere ev sahipliği yapan Leonardo, La Voce ve Lacerba'nın yayın politikası ve yöneticileri ile İtalya'nın sosyal-kültürel ve politik hayatına Birinci Dünya Savaşı ve Fütürizm bağlamında ne gibi etkiler yaptığı üzerinde durulacaktır. Özellikle bu üç derginin seçilmesinin nedeni, kurucularından birinin aynı kişi olması - Giovanni Papini - ve yayın hayatına başladıktan sonra geçen kısa sürede edindikleri başarının ardından İtalyan kültür dünyasında pek çok eleştirmen tarafından Floransa avangardını temsil eden bir düzlemde konumlandırılmalarıdır. Ayrıca, çalışmaya konu olan dergiler, İtalyan entelektüellerinin farklı görüşler çevresinde taraf olarak kümelenmesi sürecinde önemli bir kanadı temsil eder.

Çalışmaya, irdelenecek dergilere ilişkin genel bilgilerle başlamak yerinde olacaktır. Papini ve Prezzolini'nin kurduğu ve Ocak 1903-Ağustos 1907 y1lları arasında yayın hayatını sürdüren Leonardo dergisi; Papini ve Soffici'nin kurduğu ve Ocak 1913-Mayıs 1915 y1lları arasında faaliyet gösteren Lacerba dergisi ile yine Papini ve Prezzolini'nin kurduğu ve Aralık 1908-Aralık 1916 yılları arasında yayınlanan La Voce dergisi bu çalışmada araştırma konusudur. Kurucu isimlerinden de anlaşılabileceği üzere, her üç derginin de yayın hayatına başlamasında etkin görev üstlenen kişi, Giovanni Papini'dir. İtalyan kültür hayatına katkıları yadsınamayacak derecede fazla olan ve bu konuda öncülük yapan Papini aracılığıyla İtalyan siyasî, felsefî ve kültürel hayatının genel özelliklerini ve söz konusu yıllar içinde gösterdiği gelişimi gözlemlemek mümkündür.

\section{Leonardo (1903-1907)}

Kronolojik sıra ile gitmek gerekirse, öncelikle Leonardo dergisini incelemek yerinde olacaktır. Dergiye ilişkin detaylı bilgiler vermeden önce "Leonardo" sözcüğünün ne anlama geldiğini belirtmek gerekir. Bir açıdan dergi adı tarihsel ünlü bir kişiyi anımsatır: Leonardo Da 
Vinci 1452-1519 yılları arasında yaşamış ünlü mimar, mühendis, ressam, sanatçı, kısaca, çok yönlü bir bilim ve sanat insanıdır. Rönesans dönemine ve kendinden sonraki yüzyıllara damga vurduğu bilinir. Özetle teknolojide ve sanatta yeni bir dönem başlattığ söylenebilir. Diğer bir açıdan sözcügün etimolojik kökenine bakmak gerekirse, cesur veya güçlü aslan anlamına geldiği anlaşılmaktadır. Döneminin kültür dünyasını dönüştürmek, etkilemek, yönlendirmek ve sonraki yıllara etki bırakmak gayesiyle kurulan bir derginin neden bu adı aldığı bahsi geçen iki husus göz önüne alındığında daha iyi anlaşılmaktadır.

Leonardo dergisinin kurulduğu süreç, İtalya'da, özellikle de Floransa' da Ardigò, Sergi ve Lambroso'nun temsil ettiği Pozitivizm'in ruhban sınıf karşıtlığ 1 ile hızla yayıldığı yıllardır. Roma kentinin İtalyan Krallığı topraklarına dâhil edilmesinden sonra (1871) tinselliğin geri plana atılmasıyla birlikte İtalyan sosyal yaşamı en başarılı insanlarını, özellikle de gençlerini rahatsız eden boyutlarda git gide kötüleşir (Viviani 1955: 133). Avrupa'da birbiri ile yarış hâlinde olan Romantizm ve Pozitivizm çatışması mevcuttur. İtalya özelinde birliğinin sağlanmasından sonra bazı çevreler tarafından ön planda tutulan pozitivist düşünce, eleştirmenler tarafından sert bir biçimde eleştirilir. Üstelik söz konusu karşıtlık, genç aydınların durumdan vazife çıkarmaları için gerekli şartları oluşturan bir etmen olarak ortaya çıkar. Derginin kurucuları başta olmak üzere, bazı düşünürler bu kısır döngüye karşı bir şeyler yapma gereği itkisiyle pek çok genç aydınla bir araya gelerek, Leonardo dergisini dönemin sosyalkültürel değerlerine bir tepki olarak kurarlar. Dergi o dönemde yaşayan gençliğin bir eseri olarak, onların gücü, ilgisi ve çabasından ortaya çıkan bir sonuçtur. Gençler kendileri açısından "kültürel yozluk ve seviyesizlik" olarak tanımladıkları yapıyı bertaraf edecek bir üst oluşumu gerçekleştirmek isterler (Viviani 1955: 134). Söz konusu üst oluşum aslında genç yazar ve düşünürler açısından İtalyan toplumunun lâyık olduğu ve o günkünden daha üst değerlere sahip olduğuna inanılan bir düşünce sistemidir. Dolayısıyla, Leonardo'nun temsil ettiği değerler, keskin özellikler taşıyan bir yenilenme hareketini içinde barındırır: Edebî ve felsefî alanda yeşertilmesi arzu edilen Rönesans ile köhneleşmiş düşünceler ve eski zihniyetlerin metodik olarak yıkılması kapsamında, açık ve net bir biçimde ulusun siyasî alanda yenilenme ihtiyacını gidermeye yönelik bir harekete geçme kuvvetini ihtiva eder (Viviani 1955: 134).

Nicelik bakımından Leonardo dergisinin ulaştı̆̆ kitlenin dönemin şartları düşünüldüğünde oldukça iyi bir seviyede olduğu söylenebilir. Niteliksel olarak Leonardo'da çoğunlukla felsefe üzerine yazılar yayınlanmakla birlikte edebiyat ve sanat konularında da çıkan makaleler vardır. Dergi ortalama 2.000 adet basılır ve abone sayısının 1300'lere ulaştığ 1 bilinmektedir (Baldini 2018a: 11).

İçinde yeşerdikleri topluma ciddi bir yenilik getirme iddiasında bulunan dergi yazarları, bu düşünceden hareketle ünlerini yurt dışına Fransa, İngiltere ve Amerika gibi ülkelere de taşımayı başarabilirler. Nitekim Pragmatizm felsefesinin kurucuları ve savunucuları William James ve F.C.S. Schiller de yazılarıyla dergiye katkıda bulunan ünlü düşünürler ve yazarlar arasında yer almaktadırlar. Yirminci yüzyılın ilk yarısında etkili olan Fransız filozof Henri Bergson'un da dergiyi takip eden ünlü isimlerden biri olduğunu belirtmekte yarar vardır (Viviani 1955: 137). Ayrıca, bu isimlere ek olarak, dergi yönetimi kültürel yenilenme gayesiyle kapılarını dönemin en önde gelen felsefî düşüncelerine aralamaya çalışır. Önemli olan geleneksellikten uzaklaşarak yeniyi takip etmek adına Avrupa'da konuşulanları ve var olan 
felsefî, siyasî, kültürel düşünceleri İtalya'ya tanıtarak ülkede bu konular üzerine tartışılmasını ve yazılar yazılmasını teşvik etmektir. Söz konusu düşünürler arasında Friedrich Nietzsche önemli bir yer tutar. Felsefî akım bağlamında ise Pragmatizm'in o dönem içinde kabul gören bir hareket olduğu bilinmektedir. Ancak dergi her ne kadar İtalyan Pragmatizminin yayın organı niteliğini taşısa da mistik bir boyutunun olduğu yadsınamaz, çünkü dine karşı insanın içsel güçlerine hitap eder (Martini 1956: 11). Aslında silip atmaya çalıştı̆̆ tinselliğin yerine benzer öneme sahip bir öge koyma gereği hissedilir. Her ne kadar dönüşümün sert eylemler gerektirdiği düşünülse de, bazı hususlarda kültürel birikimin ve ortak hafızanın kolay ve bütünüyle silinemeyeceği de açıktır.

"Floransa avangart hareketi” olarak adlandırılabilecek kültürel yenilenme çabasının öncü mecralarından biri olarak tanımlanabilecek dergi bünyesinde yer alan yazarlar, kişiliklerinde var olan gerek iddialı ve hırslı olma özellikleri gerek geleceği şekillendirme tutkuları sayesinde kültürel alanda değişimin fitilini ateşlerler. Derginin amaçları dönemin yazarlarında öyle bir ulvî hava yaratır ki İtalya'nın entelektüel ve politik anlamda yeniden dirileceği, köhneleşmiş iç çekişmelerin yerine Avrupa'da iddia sahibi olabilecek ve Roma İmparatorluğu döneminde yaşandığ1 üzere geniş bir coğrafyada hüküm sürebilecek ve örnek teşkil edebilecek bir zenginliğe kavuşulabileceği hayali şekillenir (Viviani 1955: 138). Yerel kökenli olmakla birlikte avangart sanatın ilk dergisi olma özelliğine sahip olan Leonardo'da yazma imkânı bulan düşünürlerin bu geleneği kuracakları ve yönetecekleri müteakip dergilerde de temsil ettikleri bilinmektedir. Modernizmi çağrıştıran bu akım, çekirdek felsefeyi oluşturan ve derginin yayın istikametini belirleyen önemli bir unsur olma özelliğini korur. Söz konusu avangart akımın içinde Fütürizm, Dadaizm ve Sürrealizm akımlarına dâhil olan sanatçılar, inandıkları yeni fikirleri geçmişin ağırlığına karşı durarak cesur bir biçimde savunmaktadırlar (Baldini 2018a: $8)$.

İtalya'nın bu denli dışa açılmasını isteyen genç düşünürler, adeta ruhlarında var olan savaşçı ruhu ve zorlukların üstesinden gelebilecek azme sahip olduklarını göstermek için çaba gösterirler. Ancak çok sayıda genç yazarın dâhil olduğu bu hareket daha ilk sayıdan itibaren farklı gruplara bölünecek ve herkesin kendi yolunu çizeceği bir hal alacaktır. Buna karşın Papini ve Soffici, bitmek tükenmek bilmeyen yenilenme çabalarını görece sert eleştirilerin de yer aldığı makalelerinde dile getirmeye devam ederler. Bitik Adam yapıtında belirttiği üzere Papini, İtalya'nın geçmişten gelen şanında olduğu gibi hak ettiği yere gelebilmesi için yapılması gerekenleri topluma ve yöneticilere aktarabilecek, bir nevi bu değişimin rehberini hazırlayabilecek etkinlikte ve yetkinlikte bir lider olarak görür kendini.

O dönemde kültürel atılım olarak adlandırılabilecek fikirlerin savunuculuğunu yapan Papini ve Prezzolini'nin öğrenim hayatlarında dikkat çekici bir nokta vardır. Önemli bir konuma sahip oldukları dergide yer verilen görüşlerinin ilerici, fevri, sert ve eskiyi reddeden nitelikte olduklarını belirten bu gibi öncü isimlerin liseyi bile bitirmemiş olmaları ilginç bir husustur (Isnenghi 2006: 499).

Leonardo dergisinin çıktığı yıllar İtalya'dan yurt dışına göçün yoğun olarak yaşandığ yıllardır. Güney İtalya'da yaşayan ve tarımla uğraşan pek çok aile ferdinin Amerika Birleşik Devletleri, Latin Amerika ülkeleri ve Avrupa'da Belçika gibi İtalya'ya göre nispeten iş olanağ 
ve ekonomik koşulları daha iyi ülkelere gittiği bilinmektedir. Bu göç dalgası çoğunlukla Güney İtalya'da yaşanmaktadır. Söz konusu Güneyliler aynı zamanda endüstri alanında hızla gelişmekte olan Kuzey İtalya'ya da göç ederler. Göç hareketi, genellikle yoksul ve okuma yazma oranı düşük insanların giriştiği bir eylemdir. Bu duruma ilişkin olarak dergi yazarları kitlelerin yurt dışına göç etmesini şu şekilde olumlar: Giden aç ve kaba güruhun boşalttığ 1 yerler, düşünen insanlar için daha fazla huzurlu ortamın oluşmasını olanaklı kılacaktır (Isnenghi 2006: 504). Bu ifade, aslında İtalya'da aydınların kültürel atılım konusunda ne kadar sert ve acımasız olduklarını göstermektedir. Böylesine bir tutum içinde bulunmaları, belirli bir zümrenin ülkenin istikbalini tayin edebileceği kanaatinde olmalarından ileri gelmektedir. Üstelik hedeflenen düşünce hayatına uyacak niteliklere sahip olmayan insanların bir nevi dışarıda kalması, onlar için mutluluk kaynağı olarak görülmektedir. Entelektüeller nezdinde toplumun yoksul ve daha az eğitim almış katmanlarıyla yaşanan bu ayrılık veya diğer bir deyişle, kopmanın ulusal birliğin sağlanabilmesi noktasında bir tezatlık oluşturduğunu vurgulamak gerekir.

Yirminci yüzyılın ilk yıllarında halkın yavaş yavaş sınıflara ayrıldı̆̆ı görülmektedir. Öyle ki, hızla endüstrileşmeye başlayan ülkede işçi sınıfının, dinin siyasî erk üzerinde etkisini sürdürdüğü ve ekonomik olarak büyük bir güç temsil ettiği sağ hareketlerin büyümesi ve kendine çokça taraftar bulması, kentsoylu sınıfın da kaygılarını artırır. Söz konusu kentsoylu sınıf, kuzey ve güneyde farklı sektörleri temsil eder. Kuzeydeki kentsoylular girişimci ve endüstriyi merkeze alan bir özelliğe sahipken, güneydekiler ise tarıma dayalı, feodal bir yapıyı andıran bir sistemin varlığına işaret ederler. Söz konusu dönemde hareketlenen ve büyük bir taraftar toplayan sosyalist ve Katolik hareketler güneydeki tarım kentsoylusu ile kuzeydeki girişimci kentsoylusunun derin kaygılarını daha da artırır (Capelli 2011: 15).

Kendisinden sonra çıkacak olan dergilere yol gösterici nitelikte ve yayın mecrasında prova mahiyetinde olan Leonardo dergisinin yazarları nezdinde temsil ettiği düşünceleri betimlemek gerekirse, elinde mızrağı olan, merhametsiz ve kana susamış bir portre çizildiği görülmektedir (Isnenghi 2006: 500).

Leonardo'nun yayın hayatının son bulmasından sonra toplumun, özellikle de kentsoylu sınıfın içine düştüğü bunalımdan vazife çıkaran Floransalı entelektüeller ve tabii bunlar arasında ön saflarda bulunan Papini, yeni bir derginin hayata geçmesi için yoğun çaba gösterir. Leonardo ile edindikleri deneyim yeni derginin daha başarılı sonuçlar alabilmesinin de önünü açacak yeni deneyimlerin kazanılmasında önemli bir rol oynar. La Voce dergisi, işte bu tür bir deneyimin sonucu olarak, Papini ve Soffici liderliğinde kurulur. Birinci Dünya Savaş1 arifesinde İtalyan dergiciliğinin en iyi örnekleri arasında sayılan La Voce, İtalyan sanatını daha önce kurulan dergiyle tohumları atılan Avrupa avangart sanatı seviyesine taşımayı başarır (Dalembert 2018: 25).

\section{La Voce (1908-1916)}

Leonardo'ya nazaran daha edebî özelliklere sahip olan La Voce dergisi, düşünce bağlamında edebiyatın ilham ve heyecan veren yapısının ifadesi olarak ortaya çıkmaktadır (Martini 1956: 136). 
Derginin adını irdelemek gerekirse, "voce" adı Türkçeye "ses" olarak çevrilebilir. Yayımlandığı dönemde avangart sanatın ve kültürün sesi olmayı hedefleyen dergi yönetimi ve yazarları, yirminci yüzyılın başta aydın çevreleri olmak üzere pek çok toplumsal kesime seslerini duyurmak isterler. Derginin adında âdeta bu isteğin tezahürü vardır.

Dergide yazıları yayınlanan pek çok yazar, İtalyan kültürünü modern dönemin standartlarına çıkartabilmek için çalışır. Bu gaye ile Floransa avangart sanatının gelişmesine ön ayak olurlar. Bu minvalde Fransız avangart sanatı, yol gösterici bir rol üstlenir. Dolayısıyla, İtalyan kültürünün Avrupalılaştırılması sürecinde, şiirin öne çıkan nitelikleri olan Fransız avangart geleneğini yüzyılın başı itibariyle uygulayan Soffici gibi şairler ön plana çıkar (Dalembert 2018: 29).

La Voce dergisinin yazarları "vociani" olarak adlandırılırlar. Bazı ön yargıların kökleştirilerek eleştiri almadan kabul edildiği savaşçı bir dergi isterler. Özellikle de ulusal edebî ve sanatsal sistemin gelişiminde halk kültürünün alışılagelmişin dışındaki özellikleri üzerine tehlikeli düşüncelere sahiptirler (Billiani 2011: 70).

1908 yılında yayın hayatına başlayan La Voce dergisinin İtalyan kültüründeki önemini belirtirken şu hususun da altını çizmek gerekir: Dergi, İtalyan aydınlarına siyasî konularda da fikir beyan etme olanağı sağlar. Bu nedenle bir önceki yüzyıla nazaran yirminci yüzyılın ilk çeyreğinde, politika ve kültür meseleleri bir arada ele alınır. Yazarlar, basın-yayın organlarını daha geniş kitlelere erişebilmek amacıyla kullanırlar; Prezzolini'nin La Voce dergisinde bu kültürün en yüksek değerleri temsil edilir (Vittoria 2015: 507).

Kültürel ve ahlaki alanda ortak bir amaç doğrultusunda kendilerine yön çizen dergi yazarları bunun daha ötesinde bir görev üstlenmek isterler: La Voce' yi aklın ve insani değerlerin egemen olduğu yeni bir tinsel dünyanın tasarlanmasında gereken entelektüel yapıyı oluşturan bir dergi haline getirme idealleri vardır (Del Puppo 2000: 46). Zira bir önceki yüzyılda yaşamış olan Nietzsche klasik anlamda tinsel dünyanın yıkıldığını haber vermiştir. Yeni şartlara göre insanlığın ve kültürün yeni bir düzleme oturtulması gerekir. Dergi yazarlarının bu soruna kayıtsız kalmadıkları görülmektedir.

Bu bağlamda bakıldığında, La Voce dergisi, "dergiler yüzyılı" olarak adlandırılan yirminci yüzyılda önde gelen ve İtalyan toplumsal yaşamı üzerinde etkisi büyük olan bir dergi olarak ortaya çıkar. İtalya'da yöneticilik pozisyonunda ve bürokraside görev alacak kişilere ülkenin ihtiyaçlarına göre temel niteliklerin kazandırılması düşüncesi savunulur. Bu ülküye ilişkin olarak Prezzolini, 1908-1914 yılları arasında dergide yöneticilik yaptığı sırada yeni İtalyan idareci sınıfının yetişmesi beklentisiyle, dergiye dürüst, yetenekli, farklı eğilimleri ve ayrı öncelikleri olan bir toplumu ortak paydada buluşturan bir hüviyet kazandırmayı amaçlar (Langella 2004: 12).

Dergiyi etkili bir konuma getirmek için yoğun çaba gösteren Prezzolini dergide iş birliği yaptığı yazarları şu sözcüklerle tanıtır: "Farklı inançlardaydık ve ayrı taraflardaydık. Ancak bizi birleştiren tek şey gerçeklik olgusuydu” (Martini 1956: 103). Prezzolini'nin cümlelerinden de anlaşılacağı üzere, derginin bileşenleri her ne kadar farklı dünya görüşünde olsalar da, yegâne amaç, İtalyan kültürü için gerçeklik arayıştır. 
La Voce dergisi başlarda edebiyat, felsefe ve sanat alanlarında fikir üretilen bir yayın organı olarak düşünülse de, Libya'ya müdahale tartışmaları konusunda ortaya çıkan fikir ayrılıkları, başta benimsenen ana felsefenin tamamen tersi bir yönde hareket edilmesine neden olur (Del Puppo 2000: 45). Bir nevi savaşa yönelik geliştirilen bu olumlu tutum, derginin fikir dünyasındaki istikametini büyük oranda değiştirecek bir nitelik kazanmasına neden olur.

Nitekim temel kuruluş amacına ters düşecek biçimde, dergide savaşa doğrudan veya dolaylı olarak geniş yer verildiği görülür, çünkü muhtemel bir savaş sonucunda İtalya'nın ideallerinin gerçekleştirilebileceği ve aklın ön planda tutulduğu "kültürel bir ordu" hâline dönüşme fikri vardır (Magni 2015: 50). Kültür ordusu kurma gayesinin temelinde, kendi medeniyetini savunma düşüncesi yatar. Prezzolini, mensubu olduğu kültürün yalnızca güç kullanarak barbarlardan korunabileceğini savunur (Magni 2015: 41).

Daha önce de söz edildiği üzere, Avrupa devletleri arasında sömürge bulma yarışında geri kalmasından ötürü, 1911 Trablusgarp Savaşı sırasında Libya'da İtalya'nın sömürge toprakları kazanabilmesinin en büyük destekçileri arasında derginin yazarları bulunmaktadır. Savaş konusunda yazılan makaleler o denli serttir ki, açık bir şekilde bazı basın-yayın organlarına yönelik düşmanca bir tutum sergilenir. Hatta savaşın eleştirildiği, savaşa katılan askerlerin moralini bozacak biçimde yayınlar yapan dergilerin kapanması ve sansür görmesi önerilir (Dalembert 2018: 26).

Dergide yazıları yayınlanan yazar, edebiyatçı ve düşünürlerin savaşa müdahil olmakla hedefledikleri bir amaç vardır. Savaş, onlara göre, İtalyan toplumunun varlığını garanti altına almak, refahını artırmak, gelecek kuşaklara övünecekleri bir ülke bırakabilmek için ve toplumun modern yaşama uyumunu hızlandırmada, her ne kadar yıkıcı etkileri olsa da toplumun bir arada ortak bir hedef için çabalamasının önünü açacak ve birlikteliği yüceltecek bir araçtır. Dolayısıyla savaşı her alanda ilerlemenin ve gelişmenin firsatı olarak gören "müdahalecilik" (interventismo) yanlıları, 1911-1912 yıllarından itibaren (Osmanlı İmparatorluğu ile girişilen Trablusgarp Savaşı bu döneme denk gelir) savaş düşüncesini ülkenin ideallerinin gerçekleşmesi noktasında birleştirici bir unsur ve ulusal anlamda toplumsal dayanışmanın gerçekleşebilmesinin bir aracı olarak görür (Vittoria 2015: 514). Fernando Agnoletti'nin Canto di guerra (Savaş Şarkısı) başlıklı yazısı derginin İtalyan müdahaleciliğini en şiddetli biçimde savunduğu sayfaların başında gelmektedir. Agnoletti düşmana karşı sürdürülen savaş ile iç savaşa ilişkin olarak yazısında şu sözcüklere yer verir:

"Dışardan bir düşman yalnızca düşmandir ve bu kadar. Şayet mağlup edilirse, ayağa kalkması ve çekip gitmesi için ona yardım eli uzatılır; eğer bizi mă̆lup ederse, ayă̆a kalkılır ve savaş yeniden başlar. Fakat içerdeki düşman pis bir kanserdir, sakalda kökü kazınması gereken bir iltihaptır. İç savaşlarımız çok sertti ve hâlâ öyle, çünkü biz diğer tüm toplumlardan daha sağllklı ve zekiyiz. İç düşmanlar şehrimizden ve ulusumuzdan çekip koparılmalıdır [...]” (Agnoletti 1915: 732).

Savaş konusundaki görüşlerde o denli samimidirler ki, inandıkları bu değer uğruna bazı yazarlar bizzat savaşa katılmışlardır. Savaşa katılanlardan bazıları cephede hayatlarını kaybetmişlerdir. Temmuz 1915'te hayatını kaybeden Renato Serra bu duruma örnektir. Derginin bir sayısı Serra'ya ithaf etmiştir (Magni 2015: 38). 
Siyasî otoritenin politikaları bağlamında savaşa ilişkin yazılan yazılarda, bizzat cephede bulunan kimi yazarlar orduyu ve askerleri övebiliyor ve kötüleyebiliyorlardı (Magni 2015: 39). Hiç kuşkusuz bu öz güveni ve hakkı kendilerinde bulmalarının arkasında bir sebep vardır: Onlara göre, bu konuda söz söyleyebilecek başka erkin bulunmaması ve ülke için neyin iyi olduğuna karar vermede yetkin olduklarını düşünmeleri.

La Voce dergisi döneme göre nispeten uzun bir yayın hayatına sahip olmuştur. Söz konusu savaşlarla geçen çalkantılı süreçte derginin yayın politikalarının değişkenlik gösterdiği söylenebilir. Bu nedenle derginin yayın hayatını iki döneme ayırmak mümkündür. Ayrımı yaparken dikkate alınan hususların başında derginin yayın çizgisi gelmektedir. Birinci Dünya Savaşı döneminde dergi beyaz La Voce adını alarak İtalyan toplumunun yüzyılın başındaki sorunlarını kasıtlı bir biçimde görmezden gelen edebî bir dergiye dönüşür (Magni 2015: 37). İlk kurulduğu yıllarda savaş yanlısı yayınlara ağırlık veren dergi yazarları geçen süreçte edebiyata ağırlık vermeye başlamıştır. Bunun nedenleri arasında, savaşın getirmiş olduğu yıkım ve kültürel anlamda beklenen itki gücünü yaratamamış olması sayılabilir.

Savaş izleğinin ötesinde, derginin kuruluşundaki temel amaçlar arasında İtalya'daki kültürel seviyeyi düştüğü yerden yukarılara çekmek vardır. Doğal olarak toplumda kendine taraftar bulmak isteyen yazarlar azınlık dahi olsa, kendilerini daha iyi anlayabilecek bir kitleye ulaşmayı hedefler.

Zaman içinde dergide yer alan farklı görüşler iki ana çizgide karşı karşıya gelir: ilki doğrudan hareket eden, öncü olan ve "vociana" olarak adlandırılan gelenekten koparak sanatsal ve biçimlendirici manada özgürleşmeyi temsil ederken, diğeri Milanolu Fütüristlerin gözünde İtalyan ve yabancı düşmanlığına bir cevap olacak tartışmaların yaşandığı bir dergi yaratma isteğidir (Del Puppo 2000: 52).

La Voce dergisi, içinde barındırdığı farklı görüşten pek çok düşünürün yazılarıyla zenginlik kattığı bir mecradır. Ancak İtalyan kültür hayatına katkısı yalnızca kendi varlığıyla ölçülemez. Görüş ayrılığı yaşayan yazarların ayrılarak başka dergiler kurması, İtalyan düşünce dünyasının çeşitlenmesine dolaylı ve doğrudan bir katkı olarak görülebilir. Amaç ve ilgi alanlarında yaşanan ayrımlardan dolayı kurulan dergiler şunlardır: Papini ve Amendola'nın 1909 yılında kurduğu L'Anima, Salvemini'nin 1911-1920 yılları arasında yaşayan dergisi L'Unità ve 1913-1915 y1llarında faaliyet gösteren Lacerba dergisi (Baldini 2018b: 154).

Görülmektedir ki, La Voce bir dergi olarak var olmasının yanında entelektüellerin "yetişme" sürecini tamamladıkları, kendilerini keşfettikleri ve yeni bir kültürel girişimde bulunma cesareti edindikleri bir olgunlaşma mecrası olarak işlev görmüştür.

\section{Lacerba (1913-1915)}

Yirminci yüzyılın ilk çeyreğinde etkili olan bir diğer dergi ise, daha önce değinilen Lacerba'dır. İtalyan avangart kültürünün en bilinen yayın organlarından biri olarak kabul edilen derginin adı özel bir anlam barındırır: "Derginin adına ilişkin bilgi vermek gerekirse, harfitarif ile sıfat arasındaki kesme işaretinin düşüşü-Cecco D'Ascoli'nin Latince 'de 'Acerba etas' halk dilinde ise 'L'Acerba' hâlini alan, on ikinci yüzyılda yazılan kitabından alınmıștır- derginin 
kurucularının, yani Papini ve Soffici'nin canlandırdiğı Konformizm karşıtı bir ruhu ifade etmekteydi" (Bartolini 2010: 21). Özetle, derginin anlamı dünyevi hayata ilişkin sorunlara göndermede bulunmaktadır. Benzer bir şekilde dergide savunulan düşünceler de bir nevi yaşamdaki sorunlara çare bulmak gereksiniminden doğarlar.

Lacerba dergisinde yazıları yayımlananlar arasında yalnızca İtalyanlar yoktur. Dergi kazandığı şöhret sayesinde pek çok Avrupalı yazar ve düşünürün dikkatini çeker ve nitelikli yayınların yapıldığı bir mecra olarak kültür ve sanat dünyasından önde gelen kişilerin yazılarına yer verilen bir nitelik kazanır. İtalyanca, İngilizce ve Fransızca yayın yapan yazarlar arasında Max Jacobs, Apollinaire, Mac Delmarie, CRW Nevinson, Theodor Daubler, Anna De Pruraux ve Roch Grey (Helene Oettingen takma adiyla yazar) say1labilir. Buna ek olarak Pablo Picasso, Anna Gerebzova ve Alexander Archipenko'nun da bazı çizimleri dergide yer alır (Sica 2015: 736). Dergide yer alan isimlere bakıldığında, yüzyılın sanatında söz sahibi olan ve sanata, kültüre yön veren insanların söz konusu olduğu görülmektedir. Bu açıdan Lacerba, sanatçıların seslerini duyurduğu veya bazıları nezdinde ilk tecrübesini edindiği bir yayın aracı olarak belirmektedir.

O dönem çıkan dergilere mensup yazarların farklı edebî, felsefî ve politik akımları desteklemelerinden ötürü entelektüeller arasında bir rekabet ortamı oluşur. Hatta farklı görüşlerin başını çeken dergilerde yazdıklarıyla kültürel savaşın alevlenmesine katkıda bulunurlar. Örneğin, Lacerba yazarları ile Milano merkezli Marinetti, Boccioni ve Carra'nın başı çektiği grup arasında ateşli kültürel tartışmalar yaşandığı bilinmektedir.

Derginin hitap ettiği kesim, toplumun görece ekonomik ve sosyal olarak daha üst katmanlarıdır. "Lacerba iyi ĕ̌itim almış insanlar, edebiyat tutkunlart ile orta-üst sınıf genç entelektüelleri, sanatın ve toplumun yenilenmesi konusuna hassasiyet gösteren, irrasyonalist ${ }^{1}$ kültüre ilgi duyanlart hedefler" (Gragnani 2015: 56). Bir taraftan siyasî olarak ülke bütünlüğünü tamamlama amacı güdülürken, diğer taraftan kültürel alanda yenilenme için eskiye ait bazı değerlerin inkâr edilmesi gereği savunulur. "Lacerba uzun süredir Toskana'da var olan ruhban sınıf karşıtı geleneğin devamı olarak kültürel alanda yenilenme mücadelesinde söz konusu gruba karşıtlığı ilke edinen bir fikri okurlarına aşılamıştı" (Baldasso 2018: 56).

Dergide yer alan konuları iki ana izleğe ayırmak mümkündür: ilki siyasî, diğeri ise Fütürist çizgidedir. Savaş döneminin doğal bir sonucu olarak, dergide siyasî, kültürel ve ekonomik alanlarda çalkantılar yaşayan İtalyan halkının belli kesimine hitap eden yazılar yayınlanır. Bu kapsamda o yıllarda çıkan dergi ve gazete gibi basın-yayın organlarında savaşa dair görüşler sıkça dile getirilir. Birinci Dünya Savaşı konusunda siyasetçilerden daha cesur bir biçimde ifade edilen görüşler arasında ülkenin savaşta yer alması gerektiği ve bu durumun kültürel dönüşümün, değişimin yaşanması için büyük bir firsat olduğu vurgulanır.

Bu bağlamda, dergide Birinci Dünya Savaşı ile ilgili yazılan yazılara değinmek gerekirse, 15 Ağustos 1914 tarihli dergide savaş teması oldukça hâkimdir ve Almanya, Avusturya-

\footnotetext{
${ }^{1}$ İtalya'nın 1861 yılında gerçekleşen birleşmesinden sonra Birinci Dünya Savaşı sonuna kadar kuzeyde bulunan ülke toprakları dışında bazı bölgeleri ana vatana dâhil edilmesini savunan kimselere verilen ad.
} 
Macaristan İmparatorluğu, İngiltere, Fransa ve Rusya arasındaki savaşa ilişkin yazılar dergide epeyce yer kaplar. Bu tutumun özel nedeni ise o zamanlar savaş hususunda tarafsız olan İtalyan devletinin savaşta taraf olmasına dair propaganda yapmaktır (Föcking 2017: 142). Entelektüeller, savaş aracılığıyla İtalya'nın modern bir toplum olabileceği, zamanı yakalayabileceği ve büyük kültürel adımlar atabileceği görüşündedirler. $\mathrm{Bu}$ amaç doğrultusunda politikacıları etkilemek, ana hedeflerden biridir.

Siyasete yönelik eleştirilerin bu denli yoğun ve sert olduğu dergide dönüm noktalarından biri de 1915 yılı Ağustos ayında yaşanır. Söz konusu tarihten itibaren dergi yönetimi yayın politikasına ilişkin yeni bir karar alır. Karara göre; 15 Ağustos 1915 sayısı itibariyle Lacerba politika alanında yayınlar yapacaktır. Bu kararı, "teorik ve sanatsal etkinliklerimize kaldı̆̆ımız yerden devam ettireceğiz” (Föcking 2017: 142) ibaresiyle duyururlar.

Politika alanında eleștiri yapanlardan biri de Papini' dir. Papini, dönemin hükümetine ağır suçlamalarda bulunur; İtalya'nın geleceği için gerçekleşmesi gereken ve "radikal” olarak adlandırılabilecek fikirlerini şu biçimde ifade eder:

"Salandra hükümetinin ödleklik olarak adlandırılan diplomatik eylemlerine açık bir biçimde göndermede bulunmanın dişında politik arenada gerçek manada düşman eksikliği vardır, Papini 'nin savaştaki düşmanları yalnızca Almanlar değil, eski evler ve eski olan her şeydir. O, yalnızca Fütürizm'in savunduğu eski karşıtlı̆̆ına değil, aynı zamanda ve bilhassa, adilerin, zaylfların ve intihar etmeye bile cesareti olmayanlarin yer aldiğı dünyanın tek temizliği olarak savaş fikrine göndermede bulunur” (Föcking 2017: 145).

"Dünyanın temizliği” ifadesine bakılırsa, yazarın kendi vatandaşlarının ölümünden hiçbir rahatsızlık duymadığı anlaşılır. Hatta bu durumu daha ileri götürerek ödleklerin ve riyakârlık yapanların ölümünü olumlayan bir yazı kaleme alır. Yazının günümüz şartlarından çok, tüm Avrupa'da yaşanan siyasî, toplumsal ve ekonomik çalkantıların yaşandığı bir dönem bağlamında değerlendirilmesi gerekmektedir. Papini'nin dergide yer alan 1 Ekim 1914 tarihli yazısından kısa bir bölümü incelemek, derginin yayın politikasına dair fikir sahibi olmak açısından yararlı olacaktır.

"Ilık anne sütünden ve kardeş gözyaşlarından sonra artık kara kandan soğuk bir banyo gerekiyordu. [...] Ăgustos'un kuraklığında iyi bir kanla yıkanma gerekiyordu; [...]. Ödlekliğin, diplomasinin, riyakârlığın öğlen uykusu bitti [...]. Kardeşler kardeşleri ve sivilleri öldürmede ve vahşileşmede her zaman iyidirler: [...]. Sayımı fazla. Savaş Malthusvari bir operasyondur. [...]. Savaş sonunda tarıma ve modernliğe fayda sağlar. [...] Savaşı seviyoruz ve savaş sürdükçe gurme gibi keyif allyoruz” (Papini: 1914: 274).

Dergide politikacılara karşı ağır ithamlarda bulunulur. Derginin okuyucularına ilişkin olarak şu ifadelere yer verilir: "Giolitti'ye ölüm! [...] Onlar arasında kesinlikle iki dergi tarafindan pompalanan şiddet içeren propaganda havasinı soluyan Lacerba ve La Voce okuyucuları vardır" (Gragnani 2015: 66). Buna ek olarak, dönemin politikacılarına karşı takınılan tutum o denli serttir ki, 1 Ekim 1914 yılında Appello (Çağrı) başlığıyla yayınlanan 
bildiri niteliğindeki yazıda önce hükümete sert eleştiriler yapılır, daha sonra İtalyan toplumunun istekleri dört maddede özetlenir:

"1. Özgür eylem planımızın yeniden hatırlanmasılla üçlü ittifak anlaşmasının hızlı bir şekilde resmi olarak iptal edilmesi.

2. Artık çok gülünç ve son derece tehlikeli olan tarafsızlık tutumumuzun mümkün olan en kısa sürede sonlandırılmast.

3.Geç bir saldirı rezilliğine sebebiyet vermeden önce Avusturya-Macaristan Imparatorluğu'na karşı savaş ilan edilmesi.

4. Bizi aşağılamalardan, kötü sürprizlerden, gizli anlaşmalardan ve yıkımlardan korumayı garanti eden, yarım yüzyıl boyunca İtalya karşıtı bir politika güden üçlü itilaf devletleri ile politik yakınlaşma olması" (Lacerba 1914: 1).

Derginin Birinci Dünya Savaşı yıllarında sayfalarında sıkça yer verdiği görüşlerin ötesinde, çeşitli sayılarında sıkça yer verilen Fütürizm akımı ile ilgili görüşlere de değinmek gerekir. Bu hususta şunları belirtmekte yarar vardır: Lacerba dergisinin ilk Fütürizm öncesi dönemi oldukça kısa sürmüştür. Derginin üçüncü sayısında yer alan Papini'nin Fütürizmin Manası adlı makalesinde, derginin amaç ve stratejisinin Marinetti'nin hareketi ile uyumlu olabileceği üzerinde durulur (D’Auria 1982: 19).

Tüm tartışmaların ve görüşlerin yanında, dergiyi Fütürist hareketin propaganda araçlarından biri olarak düşünmek de mümkündür. Derginin 1913 yılı Ekim ayında yayınlanan iki sayısında Papini derin bir ayrım yaşar. 1 Ekim'de yayınlanan makalesinin başlığı Freghiamoci della politica (Politikayı Umursuyoruz) iken, yazar 15 Ekim'de çıkan yazısında önceki yazdıklarını inkâr eden Fütürist bir çizgide konumlanır (Della Terza 1984: 154). Bu tutum, dergide Fütürist harekete yakınlaşmanın öncü adımlarından biri olarak görülebilir. $\mathrm{O}$ sıralarda Marinetti'nin Fütürizm çizgisine yakın olan Lacerba'da İtalyan toplumuna yönelik bazı çağrı ve önermelerde bulunulur: "Marinetti tarafından Lacerba için kaleme alınmış Fütürist program kapsaminda, Marinetti'nin manifestosunda da belirtilen ve dergi okurlarının aşina olduğu bilinen şu noktalar tekerrür ediyordu: güçlü bir ordu, 'Italyan' olarak adlandırılmaktan gurur duyan bir ulus, sert ve sömürgeci, yayılmacı bir politika, Italya'nın öncülü̈̆̈̈, yani panitalyancılık” (Della Terza 1984: 155).

Fütürizm hakkında dergi yazarlarının görüşleri, önceleri İtalya'nın gelenekselliğine dair bir çare olacağı düşünülse de, avangart kültür etkisiyle bu durum farklı bir boyuta evrilir. Artık iddia, İtalyan Fütürizm hareketinin eksiklerini gidermek ve bu felsefeyi daha da ileri bir boyuta taşımaktır. “Önce Fütürizmin İtalya'nın geçmişini tedavi etme amacı taşıdı̆̆ı düşünülüyordu, şimdi ise Lacerba Fütürizm 'in kendisini iyileştirmek istemektedir” (Baldasso 2018: 52).

Marinetti'nin Fütürist hareketinden belli başlı noktalarda ayrılık yaşansa da, dergide hâkim olan görüş Modernist bir İtalya'nın kurulmasıdır. "Yaklaşık bir yıl boyunca Marinetti ve hareketi ile aynı cephede yer alan Lacerba dergisi Levenson'a göre kendi yapısı içinde Modernizmi şekillendiren yenileşme yarışında ana arteri temsil eder" (Baldasso 2018: 35). 
Dergide Marinetti sonrası Fütürist programın liderlerinden biri olan Papini’nin Fütürizm ile ilgili görüşlerini daha iyi kavramak için şu ifadelere bakmak gerekir: "Il significato del futurismo (Fütürizm 'in Manası) başlıklı bir yayınında Papini Fütürizm hakkında 'araştırmacı ve yenilikçi Avrupa'ya giriş izni belgemiz Fütürizm'dir' der ve İtalyan Modernizm'inin eksikliğinin ve İtalyan sanatının uluslararasılaşması gerekliliğinin bilincinde olduğunu aktarır" (Föcking 2017: 135).

\section{Sonuç}

Floransa avangart sanatının en önemli temsilcileri olarak kabul edilen Leonardo, La Voce ve Lacerba dergilerindeki yazarlar, genel bir değerlendirme ile, savaşa sıcak bakar, hatta toplumun daha modern bir seviyeye gelmesinde savaşı önemli bir araç olarak görürler. Ancak savaş sonucunda ortaya çıkan şudur: "Birinci Dünya Savaşı umutlarını kırdı: bir sonraki tinsel kriz onları (dergilerde avangart fikirleri savunanlart) geçmişe, gerçeğin ve mananin tek kaynağı olarak dine dönemeye itti” (Baldasso 2018: 56). Geçmişe karşı öfke duyan, geçmişi silmek isteyen düşüncede olan bazı entelektüellerin savaşın yıkıcılığını, toplumlara getirdiği acıları ve savaş sonucunda istedikleri değişimlerin gerçekleşmediğini gördükten sonra geçmişe sarılmak zorunda kaldıkları anlaşılmaktadır.

Dergilerin İtalyan kültür ve düşünce hayatına etkisini kısaca özetlemek gerekirse, yirminci yüzyılın ilk yarısında yayın hayatını sürdüren dergilerde pek çok İtalyan şair ve yazarın ilk yayınları yer almaktadır. Dolayısıyla, ilerde önem kazanan yazın dünyasının isimlerinin edebiyat dünyasına girişlerinde önemli bir mihenk taşı görevi gören bu dergilerin bünyesinde edebiyat ve şiir eleştirisi üzerine de çok sayıda makaleler yazılmıştır.

İtalyan avangart geleneğinin temsilcileri olarak adlandırılan bu üç dergide İtalyan edebiyatı ve sanatının gelişme süreci açık bir biçimde görülebilir. Özellikle de Fütürizm'in geniş yer bulduğu Lacerba bu akımın tarihsel gelişiminde önemli yer tutar.

Bu çalışmadan anlaşılmaktadır ki, söz konusu dergiler İtalyan kültür, siyasî ve sosyal yaşamı üzerinde etkiler yaratmıştır. Her ne kadar başta hedeflenen bazı amaçlara tam olarak ulaşılamasa da İtalyan toplumunun daha modern bir çizgiye gelmesinde önemli bir rol oynadıkları kabul edilmelidir.

Sonuç olarak, dergilerin yirminci yüzyıl İtalyan entelektüel çevrelerine ve kültür dünyasına etkilerini incelerken, aynı zamanda Avrupa'da yaşanan siyasi, ekonomik ve kültürel gelişmelere doğrudan veya dolaylı olarak değinildiğini de ifade etmek gerekir.

\section{Etik Beyan}

Yazar beyanına göre, "Bir Döneme Damga Vuran Üç Avangart Dergi: Leonardo, La Voce ve Lacerba" adlı çalışmamın yazım sürecinde bilimsel, etik ve alıntı kurallarına uyulmuş; ULAKBİM TR DİZİN ölçütlerine göre çalışmada etik kurul onayını gerektiren herhangi bir veri toplama ihtiyacı duyulmamıştır. 


\section{Kaynakça}

Agnoletti, Fernando (1915). "Canto di guerra". La Voce 7 (12): 731-739.

Baldasso, Franco (2018). "Rinnovamento culturale e peso del passato. 'Lacerba' e il Futurismo". Sistema periodico Il secolo interminabile delle riviste. ed. Francesco Bortolotto, Eleonora Fouchi, Davie Antonio Paone, Federica Parodi. Bologna: Pendragon. $31-57$.

Baldini, Anna (2018). "Allies and Enemies: Periodicals as Instruments of Conflict in the Florentine Avant-garde (1903-15)". Journal of European Periodical Studies 3 (1): 7-28.

Baldini, Anna (2018). "La cultura tedesca nelle riviste dell'avanguardia fiorentina (19131915)". L densità meravigliosa del sapere Cultura tedesca in Italia fra Settecento e Novecento. ed. Maurizio Pirro. Milano: Ledizioni. 147-165.

Bartolini, Simonetta (2010). "Il Futurismo e Lacerba". Luci e ombre del Futurismo. ed. Antonio Gasbarrini-Novella Novelli. L'Aquila: Angelus Novus Edizioni. 21-38.

Billiani, Francesca (2011). "Intellettuali militanti, funzionari e tecnologici, etica ed estetica in tre riviste fiorentine d'inizio secolo: Il Regno, La Voce e Lacerba (1903-1914)". The Printed Media in Fin-de-siècle Italy Publishers, Writers and Readers. ed. Ann Hallamore Caesar, Gabriella Romani, Jennifer Burns. London: Modern Humanities Research Association and Maney Publishing. 63-78.

Capelli, Pierpaolo (2011). Emeroteca Catalogo. Roma: Biblioteca Quirinale.

D'Auria, Francesca Petrocchi (1982). "Papini e la presenza della politica in Lacerba". Studi Novecenteschi, 9 (23): 5-43.

Dalembert, Maria Pia De Paulis (2018). "Giovanni Papini: poesia e attività letteraria sul fronte interno". Cahiers de la Méditerranée 97 (1): 25-38.

Del Puppo, Alessandro (2000). Lacerba 1913-1915. Bergamo: Lubrina Editore.

Della Terza, Dante (1984). "F. T. Marinetti e i futuristi fiorentini: L'ipotesi politico-letteraria di Lacerba". Italica 61 (2): 147-159.

Föcking, Marc (2017). "Amiamo la guerra? 'Der Sturm', 'Lacerba' e l'inizio della Prima Guerra Mondiale". In trincea Gli scrittori alla grande guerra. ed. Simone Magherini. Firenze: Società Editrice Fiorentina. 131-150.

Gragnani, Cristina (2015). "Lacerba e Il figlio alla guerra: agli estremi dell'interventismo intellettuale?". Annali d'Italianistica 33: 53-73.

Isnenghi, Mario (2006). "Gli intellettuali del 'Leonardo' alle soglie del Novecento". Belfagor 61 (5): 497-508.

Langella, Giuseppe (2004). Cronache letterarie italiane. Roma: Carocci Editore.

Magni, Stefano (2015). "La Voce 'bianca' e la Grande Guerra Immagini del conflitto e dei soldati". Italies 19: 37-55. 
Martini, Carlo (1956). La Voce. Pisa: Nistri-Lischi.

Papini, Giovanni (1914). “Amiamo la guerra”. Lacerba 2 (20): 274.

Papini, Giovanni (1914). "Appello". Lacerba 2 (20): 1.

Sica, Paolo (2015). “Alleanze, antagonismi e avanguardie (Lacerba, L'Italia futurista e altro)”. Forum Italicum 49 (3): 734-748.

Vittoria, Albertina (2015). 'Il 'partito degli intellettuali' e l'organizzazione della cultura dalla 'Voce' alla Einaudi”. Studi storici 56 (3): 501-527.

Viviani, Alberto (1955). La maschera dell'orco. Milano: Bietti. 